\title{
Long-Term Efficacy and Safety of Conversion to Tacrolimus in Heart Transplant Recipients with Ongoing or Recurrent Acute Cellular Rejection
}

\author{
B. SKALICKÁ ${ }^{1}$, I. MÁLEK ${ }^{1}$, M. KUBÁNEK ${ }^{1}$, J. VYMĚTALOVÁ ${ }^{1}$, J. KAUTZNER ${ }^{1}$ \\ ${ }^{1}$ Department of Cardiology, Institute for Clinical and Experimental Medicine, Prague, Czech \\ Republic
}

Received December 27, 2008

Accepted June 26, 2009

On-line August 12, 2009

\section{Summary}

Despite the widespread use of potent immunosuppressive drugs, such as cyclosporin A and mycophenolate mofetil, ongoing and recurrent cellular rejection remain a common problem after heart transplantation. We aimed to describe the long-term effects of conversion from cyclosporine $A$ to tacrolimus in patients with ongoing and recurrent cellular rejection. This was a single-centre retrospective analysis of 17 heart transplant recipients who were switched from cyclosporine A to tacrolimus due to ongoing (5 patients) or recurrent cellular rejection (12 patients). We studied long-term efficacy and safety of this approach. 167 endomyocardial biopsies were performed during a mean followup of $69.1 \pm 12.7$ months. Thirteen biopsies (7.8\%) in eight patients ( $47 \%$ ) revealed higher grades of acute cellular rejection (Banff 2). However, they were not hemodynamically significant and did not require intravenous antirejection therapy. The mean rejection score was reduced significantly. Conversion to tacrolimus was tolerated in $82 \%$ pts without any significant side effects during a long-term follow-up. In conclusion, the conversion to tacrolimus in heart transplant recipients with ongoing or recurrent acute cellular rejection was safe and effective also during a long-term follow-up.

\section{Key words}

Tacrolimus - Heart transplantation • Ongoing rejection • Recurrent rejection

\section{Corresponding author}

Blanka Skalická, Department of Cardiology, Institute for Clinical and Experimental Medicine, Vídeňská 1958/9, 14021 Prague 4, Czech Republic. E-mail: bldu@medicon.cz

\section{Introduction}

Orthotopic heart transplantation remains the most effective therapy in patients with terminal heart failure. Introduction of cyclosporine A into routine prophylactic immunosuppressive regimen has led to significant improvement of long-term survival after orthotopic heart transplantation. This success can be mainly explained both by reduced incidence and severity of acute rejection (Málek 2004). However, the risk of acute rejection continues to remain even in the contemporary era of modern immunosuppressants. Acute rejection is common in the first months after transplantation registry data show that approximately $40 \%$ of patients are treated for at least one acute rejection within the first post-transplant year (Taylor et al. 2007).

Earlier studies have shown that tacrolimus is effective in treatment of ongoing, steroid-resistant rejection (Onsager et al. 1999, Yamani et al. 2000, De Bonis et al. 2001). Less is known about the effect of tacrolimus in recurrent, low-grade rejection episodes. Such episodes do not cause extensive damage of allograft function immediately but may result in chronic vascular rejection. Our previous report demonstrated that recurrent acute cellular rejection can be significantly reduced after the conversion to tacrolimus (Dufková et al. 2006). This short-term observation was extended and the aim of our new retrospective study was to evaluate efficacy and safety of tacrolimus therapy in long-term. We preferentially assessed tolerance of tacrolimus, acute rejection episodes and survival. 
Table 1. Banff classification and point score.

\section{Point score}

\begin{tabular}{lll}
\hline Banff 0 & No rejection & 0 \\
Banff $1 A$ & focus infiltration by lymphocytes, no myocyte damage & 1 \\
Banff $1 B$ & diffuse infiltration by lymphocytes, no myocyte damage & 2 \\
Banff 2 & focus infiltration by lymphocytes, myocyte damage & 3 \\
Banff $3 A$ & multifocal infiltrations, myocyte damage & 4 \\
Banff $3 B$ & diffuse infiltration, myocyte damage & 5 \\
Banff 4 & diffuse mixed infiltration with myocyte damage, vasculitis, hemorrhage, edema & 6 \\
\hline
\end{tabular}

This was a single-center retrospective analysis, which evaluated long-term effects of conversion to tacrolimus in heart transplant recipients with ongoing or recurrent acute cellular rejection. Ongoing rejection was defined as a rejection episode refractory to intravenous administration of methylprednisolone. The term recurrent rejection described a repetitive rejection episode following transitory regression of lymphocytic infiltrates induced by anti-rejection therapy.

\section{Study group}

Seventeen heart transplant recipients were switched from cyclosporine A to tacrolimus due to ongoing or recurrent cellular rejection between April 2001 and January 2005. The study group characteristics were as follows: 5 women, 12 men, mean age $53 \pm 11$ years, mean time from orthotopic heart transplantation $27 \pm 32$ months (ranging from 2 to 90 months). All patients had normal left ventricular systolic function. Eight patients $(47 \%)$ had diabetes mellitus. Baseline immunosuppressive prophylaxis included cyclosporine A (in all patients), mycophenolate mofetil (14 patients) or azathioprine ( 2 patients) and prednisone (15 patients). Steroid-resistant rejection episodes were documented in five patients, while the remaining 12 patients had recurrent rejection of higher grades. These corresponded to Banff classification 2 and higher (Billingham et al. 1990) (Table 1). Treatment of acute rejection before conversion was based on administration of intravenous methylprednisolone in 11 patients, an increased dose of prednisone in 2 patients and antithymocyte globulin in one patient. The study group was followed until January 2009.

\section{Protocol of conversion and follow-up assessment}

Upon conversion, the first dose of tacrolimus was administered $12 \mathrm{~h}$ after the last cyclosporin A administration. The initial dosage of tacrolimus (0.1-0.15 $\mathrm{mg} / \mathrm{kg}$ ) was divided into two daily doses and plasma levels were determined following administration of five doses. Therapeutic blood levels (10-20 ng/ml) were obtained and tacrolimus was tolerated in all patients. The first follow-up endomyocardial biopsy (EMB) was scheduled 2-4 weeks after conversion. The following biopsies were planned according to the institutional protocol - during the first year post-transplant patients underwent EMB every week during first month, every two weeks until 3 months, every one month until 6 months, followed by EMB at 9 and 12 months. In the remaining time period, the study subjects followed a EMB protocol for patients at high-risk of rejection. They had usually the second EMB four months postconversion. Thereafter, EMB was repeated every 4-6 months until 2-3 years and once a year until 4-6 years post-conversion. Biopsies were performed in all patients for a minimum of four years post-conversion. All subjects had a routine echocardiographic follow-up, which was carried out during EMB visits and later every 4-6 months of follow-up.

\section{Methods of analysis}

To evaluate efficacy of tacrolimus in the treatment of ongoing or recurrent acute cellular rejection, a score of acute cellular rejection was calculated in each patient. It was based on the grading of the Banff classification (Billingham et al. 1990). Three EMB results before and all biopsies after conversion were classified using a specific number of points according to a scale (Table 1). The score was calculated as the mean value of points from three biopsies before conversion and separately from biopsies performed during the first, second, third and fourth year post-conversion. All subjects were informed about retrospective data processing and gave their informed consent. 


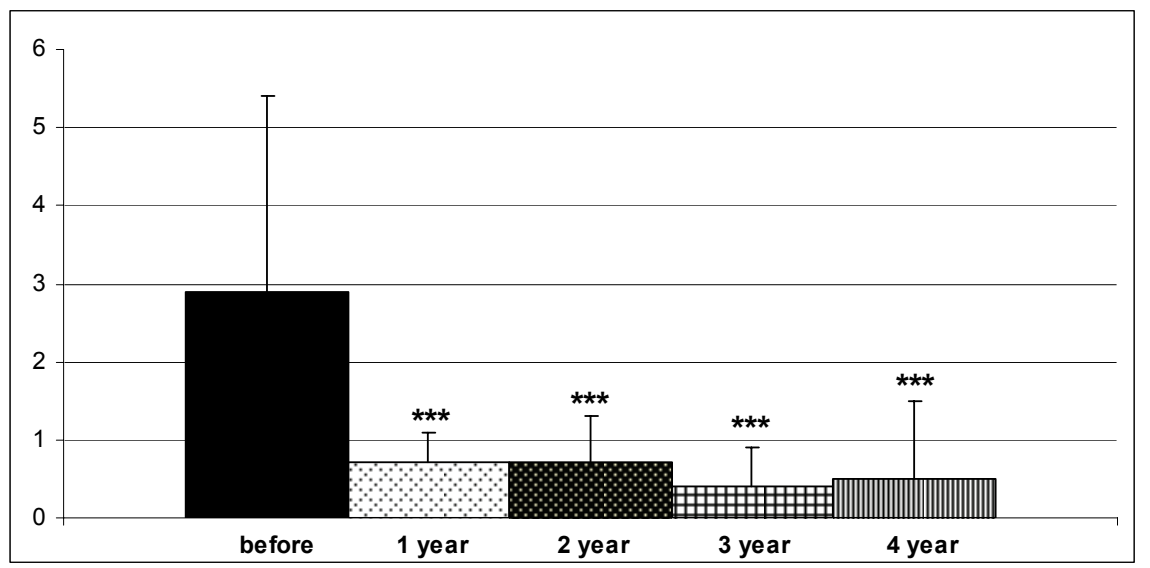

Fig. 1. Changes in the rejection score after conversion to tacrolimus. Rejection score was compared between baseline and follow-up measurement. $* * * \mathrm{p}<0.001$

\section{Statistics}

Continuous data were expressed as a mean $\pm \mathrm{SD}$.

Paired T-test was used to assess repeated measurements, considering values of $\mathrm{p}<0.05$ as significant.

\section{Results}

\section{Efficacy}

The mean follow-up of the study group was 69.1 \pm 12.7 months after conversion (range 48-92 months). 167 endomyocardial biopsies were performed during this period. Just thirteen biopsies $(7.8 \%)$ in eight patients (47\%) revealed higher grades of acute cellular rejection after conversion to tacrolimus. These biopsies were classified as Banff 2 (moderate) acute cellular rejection. Median time period from conversion to the first Banff 2 rejection episode was 12.5 months (IQR 7.8 and 18.8 months). Nevertheless, they did not induce systolic dysfunction of the graft and did not require intravenous steroids or antithymocyte globulin. The mean rejection score was $2.9 \pm 2.5$ points before conversion. It was significantly reduced during the first year $(0.7 \pm 0.4$ points $)$, the second year $(0.7 \pm 0.6$ points $)$, the third year $(0.4 \pm 0.5$ points $)$ and the fourth year $(0.5 \pm 1.0)$ postconversion as compared with the baseline value, all $\mathrm{p}<0.001$ (Fig. 1). Immunosuppressive prophylaxis at the end of the study included tacrolimus (in all patients), mycophenolate mofetil (14 patients) or azathioprine (one patient) and prednisone (16 patients). Tacrolimus trough levels decreased during follow-up (Table 2). They were comparable between patients with and without acute rejection after conversion to tacrolimus, except for the lower values in individuals with acute rejection in the $3^{\text {rd }}$ year. This difference was associated with three episodes of acute cellular rejection and may indicate the need of higher target levels of tacrolimus in this time period. Discontinuation of steroids was no feasible in this study group due to high risk of rejection.

\section{Safety}

At the end of follow-up, sixteen patients (94\%) were still alive with normal systolic function of the graft. One patient with several comorbidities died of septicemia complicated by renal and liver failure in January 2008 (81 months after conversion). Another patient was switched from tacrolimus to sirolimus because of significant impairment of renal function in June 2008 (61 months after conversion). The remaining fifteen subjects $(88 \%)$ tolerated the administration of tacrolimus without any significant side effects. Moderate increase in creatinine level was registered only in the first year after switching to tacrolimus. However, in the following years the creatinine level was comparable with baseline value (Table 2). There was no registered new-onset of diabetes mellitus. Eight patients had diabetes mellitus before conversion (four patients on intensive insulin therapy, four patients on diet or peroral medication). After the conversion to tacrolimus six patients were on insulin therapy. There was no case of malignancy during follow-up.

\section{Discussion}

Conversion to tacrolimus in heart transplant recipients with ongoing or recurrent acute cellular rejection was safe and effective during a mean follow-up of 69 months. It resulted in significant reduction of the incidence and severity of acute cellular rejection. Although $47 \%$ of subjects experienced a recurrent Banff 2 (moderate) rejection, these episodes were not hemodynamically significant and did not require subsequent use of intravenous steroids or antithymocyte globulin. 
Table 2. Freedom from acute rejection and number of rejection episodes during four years after conversion, one episode of acute rejection was documented in the sixth year of follow-up. Tacrolimus trough levels and serum creatinine as averaged from values obtained at each endomyocardial biopsy. Continuous data are shown as a median and interquartile range.

\begin{tabular}{|c|c|c|c|c|c|}
\hline & $\begin{array}{l}\text { Before } \\
\text { conversion }\end{array}$ & $1^{\text {st }}$ year & $2^{\text {nd }}$ year & $3^{\text {rd }}$ year & $4^{\text {th }}$ year \\
\hline $\begin{array}{l}\text { Freedom from acute rejection } \\
\text { after conversion (number of } \\
\text { patients) }\end{array}$ & & $12(71 \%)$ & $11(65 \%)$ & $10(59 \%)$ & $9(53 \%)$ \\
\hline $\begin{array}{l}\text { Number of acute rejection } \\
\text { episodes after conversion }\end{array}$ & & $5(38 \%)$ & $3(23 \%)$ & $3(23 \%)$ & $1(8 \%)$ \\
\hline $\begin{array}{l}\text { Tacrolimus trough levels in the } \\
\text { whole study group } \\
(\mu \mathrm{g} / \mathrm{l})(n=17 \mathrm{pts})\end{array}$ & & $\begin{array}{c}12.2 \\
(11 ; 14.2)\end{array}$ & $\begin{array}{c}11.6 \\
(10.5 ; 13)\end{array}$ & $\begin{array}{c}11.4^{*} \\
(8.8 ; 12)\end{array}$ & $\begin{array}{c}9.0^{* *} \\
(7.3 ; 11.5)\end{array}$ \\
\hline $\begin{array}{l}\text { Tacrolimus trough levels in } \\
\text { individuals with acute rejection } \\
\text { after conversion } \\
(\mu g / l)(n=8 \text { pts })\end{array}$ & & $\begin{array}{c}12.4 \\
(11.1 ; 12.9)\end{array}$ & $\begin{array}{c}12.1 \\
(11.3 ; 13.1)\end{array}$ & $\begin{array}{c}9.7 * \dagger \\
(8.6 ; 10.4)\end{array}$ & $\begin{array}{c}9.8 \\
(6.8 ; 11.6)\end{array}$ \\
\hline $\begin{array}{l}\text { Tacrolimus trough levels in } \\
\text { individuals without acute } \\
\text { rejection after conversion } \\
(\mu \mathrm{g} / \mathrm{l})(n=9 \mathrm{pts})\end{array}$ & & $\begin{array}{c}11.6 \\
(11 ; 15.5)\end{array}$ & $\begin{array}{c}10.9 \\
(9.1 ; 11.9)\end{array}$ & $\begin{array}{c}12.0 \\
(11.5 ; 12.8)\end{array}$ & $\begin{array}{c}8.9^{*} \\
(8.8 ; 11.8)\end{array}$ \\
\hline $\begin{array}{l}\text { Serum creatinine } \\
(\mu \mathrm{mol} / \mathrm{l})\end{array}$ & $\begin{array}{c}107.7 \\
(93.3 ; 126)\end{array}$ & $\begin{array}{c}121.8^{*} \\
(101 ; 130)\end{array}$ & $\begin{array}{c}106.5 \\
(90 ; 126.5)\end{array}$ & $\begin{array}{c}114.4 \\
(95 ; 129)\end{array}$ & $\begin{array}{c}105.0 \\
(101 ; 123)\end{array}$ \\
\hline
\end{tabular}

P-value for pairwise comparison between the first time period and follow-up data was coded: $* p<0.05, * * p<0.01$. P-value for comparison of tacrolimus trough levels in individuals with and without acute rejection within each year of follow-up was coded: $+p<0.05$.

Comparison with previous studies and clinical implications

These findings are in accordance with previous reports about conversion to tacrolimus in heart transplant recipients with ongoing (Onsager et al. 1999, Yamani et al. 2000, De Bonis et al. 2001) and recurrent cellular rejection (Dufková et al. 2006). The current paper provides new evidence especially in patients with recurrent rejection who were not studied by other groups. Another contribution of this study seems to be a longer follow-up after conversion. The mean follow-up in previous studies was in range of 11 to 27 months.

The main clinical benefit of conversion to tacrolimus seems to be reduced a need for repeated use of non-selective immunosuppressants, which are required for the management of moderate and severe grades of cellular rejection. Both high-dose methylprednisolone and antithymocyte globulin may be associated with significant adverse effects (Vymětalová and Málek 2005), such as infection, osteoporosis, diabetes, etc. The risk is higher, when this therapy is used repeatedly.
Furthermore, episodes of ongoing or recurrent acute cellular rejection represent a risk factor for the development of chronic rejection (cardiac allograft vasculopathy) (Valantine 2004). Conversion to tacrolimus thus provides a new approach, which might reduce both short-term and long-term complications of ongoing and recurrent cellular rejection.

Pathophysiology of acute cellular rejection and its interaction with tacrolimus

Acute rejection is mediated either by cytotoxic antibodies (humoral rejection) or more commonly by activated lymphocytes (cellular rejection). The process of acute cellular rejection is triggered by T-lymphocytes that can recognize incompatible human leukocyte antigens (HLA) of the allograft either directly or indirectly (Sheldon and Poulton 2006). Recognition of an alloantigen is followed by activation of T-lymphocytes, their clonal expansion, differentiation into effector cells and migration into the allograft (Ingulli 2010). This reaction can be suppressed by both cyclosporine $\mathrm{A}$ and 
tacrolimus. These drugs inhibit expression of interleukin2 (IL-2) and IL-2 receptor by blocking calciumdependent signal transduction via calcineurin. They also bind to different intracellular proteins, such as cyclophilin and FK-binding protein (Schreiber et al. 1992, Thomson et al. 1993). In vitro studies suggested that both drugs have a similar mode of action. On the contrary, several clinical studies have demonstrated that only tacrolimus has the ability to reverse ongoing acute cellular rejection in heart transplant recipients (Jiang et al. 2001, Ebbs et al. 2002). Inhibition of interleukin-10 (IL-10) production has been advocated as a specific mechanism that can explain the above difference (Jiang et al. 2002). IL-10 is involved in up-regulation of functional CD8+ T-cell and NK-cell local infiltration with release of cytotoxic cytokines such as granzyme B and perforin 1 (Jiang et al. 2002). However, gene expression profiles in the rat heart transplantation model showed that drug-specific effect of tacrolimus may include reversed expression of 14 other genes except of IL-10 (Erickson et al. 2003). Exact molecular mechanism explaining clinical differences between both immunosuppressants thus remains unclear.

\section{Conclusions}

In conclusion, conversion to tacrolimus in heart transplant recipients with ongoing or recurrent acute cellular rejection was safe and effective also during a long-term follow-up. It resulted in significant reduction of the incidence and severity of acute cellular rejection.

Although $47 \%$ of subjects experienced a recurrent Banff 2 (moderate) rejection, these episodes were not hemodynamically significant and did not require subsequent use of intravenous steroids or antithymocyte globulin.

\section{Conflict of Interest}

There is no conflict of interest.

\section{Acknowledgements}

Supported by the grant IGA NS-9697/2008

\section{References}

BILLINGHAM ME, CARY NR, HAMMOND ME, KEMNITZ J, MARBOE C, MCCALLISTER HA, SNOVAR DC, WINTERS GL, ZERBE A: A working formulation for the standardization of nomenclature in the diagnosis of heart and lung rejection: heart rejection study group. Heart Transplant 9: 587-593, 1990.

DE BONIS M, REYNOLDS L, BARROS J, MADDEN BP: Tacrolimus as a rescue immunosuppressant after heart transplantation. Eur J Cardiothorac Surg 19: 690-695, 2001.

DUFKOVÁ B, MÁLEK I, VYMĚTALOVÁ Y: Switching to tacrolimus in heart transplant recipients with recurrent rejection episodes. Cor Vasa 48: 421-425, 2006.

EBBS A, PAN F, WYNN C, ERICSON L, KOBAYASHI M, JIANG H: Tacrolimus treats ongoing allograft rejection by inhibiting interleukin-10 mediated functional cytotoxic cell infiltration. Transpl Proc 34: 1378-1381, 2002.

ERICKSON LM, PAN F, EBBS A, KOBAYASHI M, JIANG H: Microarray-based gene expression profiles of allograft rejection and immunosuppression in the rat heart transplantation model. Transplantation 76: 582-588, 2003.

INGULLI E: Mechanism of cellular rejection in transplantation. Pediatr Nephrol 25: 61-74, 2010.

JIANG H, YANG XF, WYNN C, SORIANO R, KRISHNAN K, FUJIMURA T, KOBAYASHI M: IL-10: A tacrolimus-specific cytotoxic mediator in ongoing allograft rejection. Transpl Proc 33: 510-513, 2001.

JIANG H, WYNN C, PAN F, EBBS A, ERICKSON L, KOBAYASHI M: Tacrolimus and cyclosporine differ in their capacity to overcome ongoing allograft rejection as a result of their differential abilities to inhabit interleukin10 production. Transplantation 73: 1808-1817, 2002.

MÁLEK I: Heart Transplantation, Cardiologist Point of View. Triton, Praha, 2004, p. 103.

ONSAGER DR, CANVER CC, JAHANIA MS, WELTER D, MICHALSKI M, HOFFMAN AM, MENTZER RM Jr, LOVE RB: Efficacy of tacrolimus in the treatment of refractory rejection in heart and lung transplant recipients. J Heart Lung Transplant 18: 448-455, 1999.

SCHREIBER SL, CRABTREE GR: The mechanism of action of cyclosporine A and FK506. Immunol Today 13: 136$142,1992$. 
SHELDON S, POULTON K: HLA typing and its influence on organ transplantation. Methods Mol Biol 333: 157-174, 2006.

TAYLOR DO, EDWARDS LB, BOUCEK MM, TRULOCK EP, AURORA P, CHRISTIE J, DOBBELS F, RAHMEL AO, KECK BM, HERTZ MI: Registry of the International Society for Heart and Lung Transplantation: twenty-fourth official adult heart transplant report - 2007. J Heart Lung Transplant 26: 769781, 2007.

THOMSON AW, STARZL TE: New immunosuppressive drugs: mechanistic insights and potential therapeutic advances. Immunol Rev 130: 71-98, 1993.

VALANTINE H: Cardiac allograft vasculopathy after heart transplantation: risk factors and management. $J$ Heart Lung Transplant 23 (5 Suppl): S187-S193, 2004.

VYMĚTALOVÁ Y, MÁLEK I: Acute rejection after heart transplantation. Kardio Forum 3: 12-15, 2005.

YAMANI MH, STARLING RC, PELEGRIN D, PLATT L, MAJERCIK M, HOBBS RE, MCCARTHY P, YOUNG JB: Efficacy of tacrolimus in patients with steroid-resistant cardiac allograft cellular rejection. $J$ Heart Lung Transplant 19: 337-342, 2000. 